\title{
The Relationship between Health State Perception on Multiphasic Personality in Chakra Meditation Experienced People
}

\author{
Sela Lim ${ }^{1}$, HeeJung Lee ${ }^{2}$ and JongDu Kim ${ }^{3}$ \\ ${ }^{1}$ Dept. of Clinical Psychology, NungIn University, Paltan-myeon, Hwaseong-si, \\ Gyeonggi-do, Korea (Corresponding Author) \\ ${ }^{2,3}$ Dept. of Naturopathic, Dongbang Culture University, Seongbuk-gu, Seoul, Korea \\ ${ }^{1}$ sera325@ nate.com, ${ }^{2}$ anahjilee57@naver.com
}

\begin{abstract}
The purpose of this study is to understand The Relationship between Meditation Experience Motivation and Perception of Health State on Minnesota Multiphasic Personality in Chakra Meditation Experienced People. This study explored correlation of People of $N$ temple Zen center's for chakra meditation experience motivation, and mental health to confirm mediation model and path of physical and emotional and social and subjective health state. To this end, data was collected from 223 survey results conducted by 250. The survey consisted of, the Chakra Meditation Experience Motivation scale, the Minnesota Multiphasic Personality Inventory-2 (MMPI- II) and The Korean Health Status Measure. The results were analyzed by SPSS macro program. The results of this study are as follow, Mercy has a positive correlation with $\mathrm{Pd}, \mathrm{Pa}$, Pt. Escapism has a positive correlation with $\mathrm{Hs}, \mathrm{D}, \mathrm{Hy}, \mathrm{Pd}$, $\mathrm{Pa}, \mathrm{Pt}, \mathrm{Sc}, \mathrm{Ma}$, Si. Self-efficacy has a positive correlation with Pd, Pt, Sc, Si. Narcissism has a negative correlation with D, Hy, Mf and a positive correlation with Ma. Emotional stability has a positive correlation with $\mathrm{Hs}, \mathrm{D}, \mathrm{Pd}, \mathrm{Pa}, \mathrm{Pt}$, Sc, Si. Physical health has a negative correlation with $\mathrm{Hs}, \mathrm{D}, \mathrm{Hy}, \mathrm{Pd}, \mathrm{Mf}, \mathrm{Pa}, \mathrm{Pt}, \mathrm{Sc}$, Si. Emotional health state has a negative correlation with $\mathrm{Hs}, \mathrm{D}, \mathrm{Hy}, \mathrm{Pd}, \mathrm{Mf}, \mathrm{Pa}, \mathrm{Pt}, \mathrm{Sc}$, Si. Social health state has a negative correlation with $H s, D, M f, P t, S c$, Si. Subjective health state has a negative correlation with $H s, D, H y, P d, P t, S c, S i$. Afterwards, the author discussed the contribution and limitation of this study, and suggestions for further research.
\end{abstract}

Keywords: Chakra meditation experienced people, Chakra meditation experience motivation, Multiphasic personality

\section{Introduction}

Recently, people who want to experience chakra meditation tend to pursue stability in mental health and make active efforts to restore their mental health. This is because they believe that chakra meditation experience conditions affect mental health [1]. In particular, chakra meditation is known to promote compassion, reality escape, self-exploration, self-love, and emotional stability, and it is known that Multiphasic personalities are believed to affect mental health [2].

Those who are compassionate have proper self-love, which reflects on themselves to explore reality, thereby achieving emotional stability based on what they have realized [3].

Article History:

Received (October 18, 2019), Review Result (December 3, 2019), Accepted (January 13, 2020) 
However, those who are not compassionate tend to use an evasive strategy that isolates themselves or avoid reality rather than seeking for solutions.

Also, when exposed to various environments, they tend to complain of discomfort of body and mind and tend to obsess over the state of health that they perceive rather than their actual state of health. At this time, they show their perception of health and various personality types.

Conversely, research on the motivational aspects and multiphasic personalities of those who have experienced chakra meditation both domestically and abroad has been very limited.

Although chakra meditation experience motivation was not analyzed in detail to look into compassion, reality escape, self-exploration, self-love, and emotional stability, and it was reported that chakra experience was beneficial to health, many studies did not use appropriate measuring tools [4].

Above all, it claims to be beneficial to mental health, but the claims were not verified by measuring multiphasic personality, and did not use measuring tools to classify mental health conditions by type to examine them in detail. Many previous studies attempted to validate the claims using a questionnaire.

There was also a limitation in that there was a lack of a scientifically standardized measurement tool. Therefore, this study aims to measure physical, emotional, social, and subjective health perceptions to measure compassion, reality escape, self-exploration, selflove, emotional stability, and health perception to measure the motivation of people who have experienced chakra meditation. do.

In addition, through the Minnesota Multiphasic Personality Inventory, various aspects of mental health are divided into, depression, hysteria, psychopathic deviation, masculinityfemininity, paranoia, obsessive compulsive disorder, schizophrenia, hypomania and introversion.

The purpose of this study is to examine how chakra meditation experience motivation and health perception correlate with each of the subfactor of multiphasic personality.

This study seeks to verify the correlation between meditation experience motivation and perceptions of health status with each subfactor of multiphasic personality.

It is believed that in the future, chakra meditation experience motivation will able to provide support in consideration of multiphasic personalities of participants when they are seeking compassion, reality escape, self-exploration, self-love, emotional stability for mental health field. In addition, the aim of this study is to prepare basic data for unique experimental and investigational research on chakra meditation experiences.

\section{Methods}

\subsection{Subjects and data collection}

This study was conducted from August 2018 to September 2010, for those who participated in the chakra meditation program operation agency in NungIn temple's Zen center of Seoul of Korea. Finally, the data total of 223 participants were analyzed [Table 1].

\subsection{Measures}

\subsubsection{Multiphasic personality}

In order to measure Multiphasic Personality, we used the Korean standardized version of Minnesota Multiphasic Personality Inventory-2 (MMPI- II) which was developed by Han, Yim, Min, Lee, Moon \& Kim [5]. 
Table 1 General characteristics of subjects

\begin{tabular}{|c|c|c|c|c|}
\hline & & \multicolumn{2}{|c|}{ Subjects } & \multirow{2}{*}{$\%$} \\
\hline & & Male & Female & \\
\hline \multirow{5}{*}{ Ages } & over the age of 40 & \multicolumn{2}{|r|}{23} & 10.31 \\
\hline & over the age of 50 & \multicolumn{2}{|r|}{77} & 34.53 \\
\hline & over the age of 60 & \multicolumn{2}{|r|}{87} & 39.01 \\
\hline & over the age of 70 & \multicolumn{2}{|r|}{29} & 13.00 \\
\hline & missing value & \multicolumn{2}{|r|}{7} & 3.14 \\
\hline & Total & \multicolumn{2}{|c|}{223} & 100.00 \\
\hline
\end{tabular}

\subsubsection{Chakra meditation experience motivation}

The questionnaire on meditation methods of subjects who experienced chakra meditation included the following: The duration of meditation, the frequency of meditation, the average hour of meditation per day, the presence of a supervisor, psychological conflicts or problems to solve through meditation, and the helpful part in solving a psychological problem. Meditation motivation scale was developed by Ha and modified by Kim [6][7]. A total of items is composed of 4 sub-factors. Sub-factors consist of compassion, escapism, selfexploration, self-love and emotional stability. The higher the total score, the higher the motivation for meditation. In this study, the total of Cronbach's a was .936.

\subsection{Data analysis}

Data collected for this study were analyzed using the SPSS 22.0 version (IBM Corp., Armonk, NY, USA) as follows. We conducted descriptive statistics to investigate the demographic characteristics of the subjects. The reliability of each variable was tested. Pearson's correlation analysis was used to examine the relationship between assumed factors. Regression analysis was used to examine the effects of chakra meditation experience motivation and Minnesota Multiphasic Personality Inventory (MMPI- II ).

\section{Results}

\subsection{Correlation analysis}

Mercy of Chakra Meditation Experience Motivation has a positive correlation with Pd $(\mathrm{r}=.182, \mathrm{p}<.01), \mathrm{Pa}(\mathrm{r}=.182, \mathrm{p}<.05), \mathrm{Pt}(\mathrm{r}=.181, \mathrm{p}<.05)$ of MMPI- II . Escapism of Chakra Meditation Experience Motivation has a positive correlation with $\mathrm{Hs}(\mathrm{r}=.289, \mathrm{p}<.01)$, D $(\mathrm{r}=.220, \mathrm{p}<.01)$, Hy $(\mathrm{r}=.183, \mathrm{p}<.05), \mathrm{Pd}(\mathrm{r}=.396, \mathrm{p}<.01), \mathrm{Pa}(\mathrm{r}=.447, \mathrm{p}<.01), \mathrm{Pt}(\mathrm{r}=.379$, $\mathrm{p}<.01), \mathrm{Sc}(\mathrm{r}=.412, \mathrm{p}<.01), \mathrm{Ma}(\mathrm{r}=.208, \mathrm{p}<.01), \mathrm{Si}(\mathrm{r}=.188, \mathrm{p}<.05)$ of MMPI- II. Self-efficacy of Chakra Meditation Experience Motivation has a positive correlation with $\mathrm{Pd}(\mathrm{r}=.146$, $\mathrm{p}<.05), \mathrm{Pt}(\mathrm{r}=.206, \mathrm{p}<.01), \mathrm{Sc}(\mathrm{r}=.147, \mathrm{p}<.05), \mathrm{Si}(\mathrm{r}=.201, \mathrm{p}<.01)$ of MMPI- II . Narcissism of Chakra Meditation Experience Motivation has a negative correlation with $\mathrm{D}(\mathrm{r}=-.157, \mathrm{p}<.05)$, Hy $(\mathrm{r}=-.172, \mathrm{p}<.05)$, Mf $(\mathrm{r}=-.222, \mathrm{p}<.01)$ of MMPI- II and a positive correlation with Ma $(\mathrm{r}=.153, \mathrm{p}<.05)$ of MMPI- II . Emotional stability of Chakra Meditation Experience Motivation has a positive correlation with $\mathrm{Hs}(\mathrm{r}=.195, \mathrm{p}<.01), \mathrm{D}(\mathrm{r}=.216, \mathrm{p}<.01), \mathrm{Pd}(\mathrm{r}=.322$, $\mathrm{p}<.01), \mathrm{Pa}(\mathrm{r}=.251, \mathrm{p}<.01), \mathrm{Pt}(\mathrm{r}=.261, \mathrm{p}<.01), \mathrm{Sc}(\mathrm{r}=.253, \mathrm{p}<.01), \mathrm{Si}(\mathrm{r}=.173, \mathrm{p}<.05)$ of MMPI- II . 
Physical health of Chakra Meditation Experience Motivation has a negative correlation with Hs (r=-.327, p<.01), D ( $\mathrm{r}=-.308, \mathrm{p}<.01)$, Hy $(\mathrm{r}=-.229, \mathrm{p}<.01), \mathrm{Pd}(\mathrm{r}=-.145, \mathrm{p}<.05), \mathrm{Mf}$ $(\mathrm{r}=-.166, \mathrm{p}<.05), \mathrm{Pa}(\mathrm{r}=-.160, \mathrm{p}<.05), \mathrm{Pt}(\mathrm{r}=-.246, \mathrm{p}<.01), \mathrm{Sc}(\mathrm{r}=-.248, \mathrm{p}<.01), \mathrm{Si}(\mathrm{r}=-.179$, $\mathrm{p}<.05)$ of MMPI- II . Emotional health state of Chakra Meditation Experience Motivation has a negative correlation with Hs $(\mathrm{r}=-.288, \mathrm{p}<.01), \mathrm{D}(\mathrm{r}=-.299, \mathrm{p}<.01), \mathrm{Hy}(\mathrm{r}=-.231, \mathrm{p}<.01), \mathrm{Pd}$ $(\mathrm{r}=-.254, \mathrm{p}<.01), \mathrm{Mf}(\mathrm{r}=-.247, \mathrm{p}<.01), \mathrm{Pa}(\mathrm{r}=-.296, \mathrm{p}<.01), \mathrm{Pt}(\mathrm{r}=-.396, \mathrm{p}<.01), \mathrm{Sc}(\mathrm{r}=-.352$, $\mathrm{p}<.01), \mathrm{Si}(\mathrm{r}=-.207, \mathrm{p}<.01)$ of MMPI- II . Social health state of Chakra Meditation Experience Motivation has a negative correlation with $\mathrm{Hs}(\mathrm{r}=-.288$, $\mathrm{p}<.01), \mathrm{D}(\mathrm{r}=-.204, \mathrm{p}<.01)$, Mf (r=$.164, \mathrm{p}<.05)$, Pt $(\mathrm{r}=-.264, \mathrm{p}<.01)$, Sc $(\mathrm{r}=-.256, \mathrm{p}<.01)$, Si $(\mathrm{r}=-.187, \mathrm{p}<.05)$ of MMPI- II . Subjective health of Chakra Meditation Experience Motivation state has a negative correlation with Hs ( $\mathrm{r}=-.427, \mathrm{p}<.01), \mathrm{D}(\mathrm{r}=-.427, \mathrm{p}<.01)$, Hy $(\mathrm{r}=-.364, \mathrm{p}<.01), \mathrm{Pd}(\mathrm{r}=-.186$, $\mathrm{p}<.01), \mathrm{Pt}(\mathrm{r}=-.274, \mathrm{p}<.01), \mathrm{Sc}(\mathrm{r}=-.264, \mathrm{p}<.01), \mathrm{Si}(\mathrm{r}=-.234, \mathrm{p}<.01)$ of MMPI- II .

\section{Conclusions}

This study analyzed a total of 223 out of 250 Chakra meditation experiences in their 40s to $70 \mathrm{~s}$ to explore the relationship between motivation and health status perception and multiphasic personality. This study explores the types of Minnesota Multiphasic Personality Inventory according to meditation experience motivation and health status for adults and women who experienced chakra meditation through an offline questionnaire for adult men and women who experienced chakra meditation program operated by NunIn Temple's Zen Center source in Seoul city of Korea. It was. Chakra meditation experience motivation included compassion, reality escape, self-exploration, self-love, emotional stability, and Minnesota Multiphasic Personality Inventory-2 was used to measure depression (D), hysteria (Hy), psychopathic deviation (Pd), masculinity-femininity (Mf), paranoia (Pa), compulsion $(\mathrm{Pt})$, schizophrenia $(\mathrm{Sc})$, hypomania $(\mathrm{Ma})$, social introversion $(\mathrm{Si})$.

The data analysis was a Pearson correlation analysis of each variable using a SPSS macro. The results showed that the motivation for compassion was positively correlated with $\mathrm{Pd}, \mathrm{Pa}$, and $\mathrm{Pt}$, which are lower measures of the Minnesota Multiphasic Personality Inventory (MMPI-II), and escaping reality had a significant positive correlation with $\mathrm{Hs}, \mathrm{D}, \mathrm{Hy}, \mathrm{Pd}, \mathrm{Pa}$, $\mathrm{Pt}, \mathrm{Sc}, \mathrm{Ma}$, and $\mathrm{Si}$. In case of self-discovery, it showed a positive correlation with $\mathrm{Pd}, \mathrm{Pt}, \mathrm{Sc}$, and Si, while self-love had a negative correlation with D, Hy, and Mf. Emotional stability was positively correlated with $\mathrm{Hs}, \mathrm{D}, \mathrm{Pd}, \mathrm{Pa}, \mathrm{Pt}, \mathrm{Sc}, \mathrm{Si}$. Physical health, a sub-factor of health status, is negatively correlated with $\mathrm{Hs}, \mathrm{D}, \mathrm{Hy}, \mathrm{Pd}, \mathrm{Mf}, \mathrm{Pa}, \mathrm{Pt}, \mathrm{Sc}, \mathrm{Si}$, and emotional health had a negative correlation with $\mathrm{Hs}, \mathrm{D}, \mathrm{Hy}, \mathrm{Pd}, \mathrm{Mf}, \mathrm{Pa}, \mathrm{Pt}, \mathrm{Sc}$, and $\mathrm{Si}$. Social health was negatively correlated with $\mathrm{Hs}, \mathrm{D}, \mathrm{Mf}, \mathrm{Pt}, \mathrm{Sc}$ and $\mathrm{Si}$, and subjective health was negatively correlated with $\mathrm{Hs}, \mathrm{D}, \mathrm{Hy}, \mathrm{Pd}, \mathrm{Pt}, \mathrm{Sc}$ and $\mathrm{Si}$.

Therefore, the correlation with the multifaceted personality of each subfactor of each variable was verified. This suggests that the motivations of meditation and health status of chakra meditation are related to various types of multiphasic personalities.

The suggestions for follow-up studies based on the results of this study are as follows. Since this study measured the chakra meditation experience motivation and multiphasic personality factors of the general public, the representativeness of the results of this study may not be accurate and limited to generalization for application to people with psychiatric diseases.

\section{Discussion}


The purpose of this study was to investigate the related of chakra meditation experience motivation between multiphasic personality on chakra meditation experienced people.

Especially, the significance of the results is as follows.

First, Yong-Gun [1] argued that chakra meditation experience motivation correlated with multiphasic Personality, and this research is consistent with this claim.

In other words, those who have chakra meditation experience motivation related with mental heal that multiphasic Personality.

The purpose of this study was to develop a mental health program using chakra meditation for adults and examine its effectiveness on their mental health.

Individuals who were willing to attend the program in NungIn university's clinical psychology institute were recruited and the five subjects (three men and two women) participated in this program except for one woman who dropped out.

The program was carried out twice a week for four weeks, having 7 sessions and each session took about fifty minutes. All data analyses were done with statistics software package (SPPS version 2.0).

Frequency analysis was conducted to identify the demographic characteristics of the participants. Also, the pre-post test total, mean, standard deviation scores of mental health were described for the experimental group. Non-parametric pre-post comparisons were analyzed in order to measure the effectiveness of this program by using Wilcoxon's signed rank test; because the number of cases was small and a control group was not included in this experiment.

The results showed that the group's total mean score of mental health was significantly decreased. In addition, Global Severity Index and depression subordinate scale scores of mental health were significantly reduced in the group.

The examination of the finding of this study suggests that the mental health program using chakra meditation could be utilized for adults' mental health and the first to provide mental health pre-test and post-test results for the chakra meditation program.

The limitation of the current study was that the subjects only consisted of the experimental group without the control group. But It was different from our survey study that Yong-Gun's thesis was experimental research designs and Subjects and data collection was small group and the survey consisted of, the SCL-90-R (Symptom Checklist-90-Revision) for mental health.

The measuring function of SCL-90-R same as Minnesota Multiphasic Personality Inventory-2 (MMPI- II ) that Measures for mental health and types of multiphasic personalities [8]. However, the effect of the chakra meditation experience effected on multiphasic personalities and related.

Second, Hawang-Ok [9] argued that chakra meditation experience motivation correlated with anxiety and depression, and this research is consistent with this claim.

In other words, those who have chakra meditation experience motivation related with mental health that anxiety and depression along with multiphasic personality.

This study examined the effect of negative life events on anxiety and depression in those who experienced meditation. Investigating whether anxiety, depression, negative life event, the motive for meditation have significant difference among individuals' gender and duration of meditation, whether negative life events have effects on anxiety and depression. For this hypothesis, demographics questionnaire, duration and performance method of meditation, the motive for meditation, negative life events questionnaire, Korean-Beck Anxiety Inventory (KBAI), Beck Depression Inventory (K-BDI-II) were conducted. A survey of 268 individuals 
was carried out for this study. 193 people were analyzed for final analysis except for 75 inadequate date by using SPSS 22.0 version (IBM Corp., Armonk, NY, USA).

The collected data were analyzed by operating descriptive statistics, t-test, Pearson correlations and regression analysis. The reliability coefficient in this research was high reliability. Men's duration of meditation was significantly higher than women's, and people over 1 year meditation experience had higher motive for meditation, especially benevolence and self-exploring, than people below 1 year meditation experience. Negative life events significantly influenced anxiety and depression.

This current study shows negative life events of individuals, who had meditation experience, had effects on themselves anxiety and depression, even though empirical research about this topic is not sufficient.

It would take more effort to intervene negative life events for those who had meditation experience with anxiety and depression. But It was different from our survey study that Hawang-Ok's survey consisted of, the anxiety and depression along with types of mental health.

It was different from our survey study that Hawang-Ok's thesis was the survey consisted of, the Korean-Beck Anxiety Inventory (K-BAI), Beck Depression Inventory (K-BDI-II) for anxiety and depression among mental health.

The measuring function of Korean-Beck Anxiety Inventory (K-BAI), Beck Depression Inventory (K-BDI-II) contained measuring function that Measures for anxiety and depression of types of multiphasic personalities.

However, the effect of the chakra meditation experience effected on anxiety and depression contained and related by mental health. Thus, we think that the chakra meditation experience motivation, the multiphasic personalities have been effective therapeutic methods for the mental health. Therefore, this suggests that chakra meditation experience motivation can be helpful for mental health.

\section{References}

[1] Y. G. Song, "The development and effectiveness of mental health program using Chakra meditation for adults," M.S. thesis, NungIn University, (2017)

[2] J. S. Lee, “A feast of Zen meditation”, Seoul, in press, NungIn Publishing Corp, (2015)

[3] H. J. Lee, "The development and effectiveness of mental health program using Chakra meditation for adults", M.S. thesis, NungIn University, (2019)

[4] S. L. Lim, "The development and effectiveness of mental health program using Chakra meditation for adults," Studies on Buddhist Art and Culture, vol.9, no.9, pp.311-331, (2017)

[5] K. H. Han, J. Y. Yim, B. B. Min, J. H. Lee, K. J. Moon, and J. S. Kim, "Korean MMPI- II standardization Study,” Korean Journal of Clinical Psychology, vol.25, pp.533-564, (2006)

[6] H. J. Ha, "Influence of meditator's psychological characteristics on experiences of mindfulness meditation," M.S. thesis, Seoul National University, (2007)

[7] K. U. Kim, "A study on the effect of duration and motive for meditation on psychological well-being," M.S. thesis, Seoul Cyber University, (2016)

[8] K. I. Kim and J. H, "Won. Korean manual of symptom checklist-90-revision," Seoul, in press, Chung Ang aptitude publishing Corp, (1992)

[9] H. O. Kim and S. L. Lim, "The effect of negative life event on anxiety and depression in those who experienced meditation," Asia Life Sciences, in press, (2019) 